\title{
Research on the Application Status of Information Technology in Classroom Teaching
}

\author{
Zhiguo Sang ${ }^{1}$, Liang Shen ${ }^{1}$, Chunhui $\mathrm{Li}^{1}{ }^{1,2, *}$ and Jie Shang ${ }^{2}$ \\ ${ }^{1}$ Center of Experimental Management, Dezhou University, Dezhou, P. R. of China \\ ${ }^{2}$ College of Chemistry and Chemical Engineering, Dezhou University, Dezhou, P. R. of China \\ ${ }^{*}$ Corresponding author
}

\begin{abstract}
Information technology is applied to classroom teaching, which integrates computer, network, audio, video, multimedia, application software, virtual system and so on. The information technology is an effective auxiliary teaching tool to change the traditional teaching modes and improve teaching effect. In this paper, based on the actual application investigation of the information technology in classroom teaching, the current situation and existing problems of the information technology as the assisted teaching tool in colleges and universities were analyzed, and then some targeted suggestions were given. The corresponding countermeasures for the information technology will enlarge its application range, promote the teaching quality, and improve cultivating students' innovative thinking.
\end{abstract}

Keywords-information technology; teaching; application status;colleges and universities; countermeasures

\section{INTRODUCTION}

Nowadays, the rapidly developing information technology is changing people's lifestyles, but also profoundly affects traditional teaching methods. The information technology is widely introduced into the college classroom teaching process, which overcomes some shortcomings of traditional teaching, stimulates teachers' enthusiasm for teaching and students' interest in learning, and improves teaching effectiveness and quality.

The goal of the information technology as an assisted teaching tool is to optimize the teaching process and improve teaching effectiveness and quality. Therefore, the information technology equipment plays an irreplaceable role in modern teaching reform. Many colleges and universities in china have continuously increased investment for the information technology equipment and enlarged its application range. However, there are some problems in the using process of the information technology. The information technology can only be an auxiliary means, not a panacea for improving the teaching effect. In order to pursue popular synchronism, some college teachers rushed to abandon the traditional teaching methods and blindly adopted modern information technology in classroom teaching. This excessive dependence will lose assisted teaching characteristics and effectiveness of the information technology. In this paper, the current situation and existing problems of the information technology as the assisted teaching tool in colleges and universities were analyzed, and then some targeted suggestions were given, which will help to enlarge the applicable range and improve the efficiency for the information technology.

\section{APPLICATION STATUS OF THE INFORMATION TECHNOLOGY In ClassRoOM TEACHING}

The information technology has been widely used in college teaching, which integrates computer, network, audio, video, multimedia, application software, virtual system and so on. However, the information technology is like a doubleedged sword. On the one hand, it can realize the more powerful teaching function by various forms of information. On the other hand, it also can cause excessive dependence for teachers and students, and weaken the original function of teachers.

The utilization rate of teaching resources by the information technology is not high. Many college teachers can insufficiently master modern teaching technology. The information technology is only employed in the common amusement, reading the news and chatting on the Internet. However, there is a lack of understanding and application for many information technology equipment invested by colleges and universities. Insufficient understanding of modern educational technology and unskilled information technology have led to a low utilization rate of information technology as teaching resources. The information technology mainly relies on multimedia, network technology, audio and video, and teachers merely carry out teaching contents through multimedia courseware.

The existing problems are as follows.

Firstly, the utilization frequency of multimedia courseware is very high. Many students reflect that they attend at least six lessons with multimedia courseware one day. The students stare at the screen in the dark classroom for a long time every day, which is easy to cause adverse reactions, such as visual fatigue and dizziness. Secondly, the using of courseware and audio-visual for a long time makes students feel bored with teaching, and then affects learning effect. Thirdly, the information is too large to be received for students. Teachers do not fully consider students' ability to accept. Moreover, the display contents in class for some teachers through the information technology are too singular and boring. Fourthly, some teachers rely on the teaching content merely according to the textbook by the information technology. Fifthly, some teachers mechanically follow teaching contents and processes in the past, and robotic students copy notes. There is no 
thinking time, so a cramming class is formed. Sixthly, sometimes students only hear teachers' voice and not see theirs body language. Therefore, the class teaching is dull, and the students' interest cannot be fully aroused, which cause less communication between teachers and students. Seventhly, the teaching speed through the information technology is fastpaced, which will inevitably reduce the learning enthusiasm and efficiency for students. Just like some students felt: the teacher spoke very quickly and students stared at the screen. There was no time to take notes and write down some important contents. After a class, although I was very tired, I felt that I could not clearly remember what I learned. Eighthly, from the psychological willingness, many students prefer the combined teaching method of information technology and traditional teaching methods, not only the information technology. If teachers blindly pursue the information technology, good teaching effect will not be achieved.

\section{The ReAsons AnAlysis For Misapplication Of ThE INFORMATION TECHNOLOGY}

\section{A. Overusing of the Information Technology}

The information technology can only be an auxiliary means as teaching tools, not a panacea for improving the teaching effect. If the information technology is used improperly or over-used, it will distract students' attention, which results in interference and inefficiency in teaching. However, some teachers completely abandon traditional teaching methods, and then the information technology is blindly employed in all teaching processes no matter what courses and teaching objectives are, resulting in losing characteristics and performance of the information technology.

In the teaching practice, the information technology can improve the teaching effect, but it is wrong to think of the information technology as a panacea for improving teaching effectiveness. Teachers excessively pursue and utilize the information technology, and rely too much on the teaching form through the information technology, which is easy to cover up the teachers' skills and wisdom. Simultaneously some teachers' basic skills training are weakened. As a result, the students turn into a spectator, and the teachers become a projectionist, as well as the information technology equipment and software change into the performers. The information technology plays a dominant role in the entire classroom teaching, and both teachers and students have lost their roles. The pre-designed teaching contents through the information technologies by the teachers command the teaching of teachers and the learning of students. However, the students' thinking is active and diverse, and it is not easy to be grasped by the teachers. This is inconsistent with modern teaching concepts. The teacher's dominance and the student's subjective status are not well reflected. As a teacher, teachers should first grasp their dominant position and role in teaching. They should not only be the commentator and the player but should design the teaching process. Through predesign and flexible operation, the functions and efficiency of the information technology teaching can be maximized. At the same time, from the relation among people, teaching content and the information technology, the basic teaching rules and requirements of the information technology should be studied in order to make information technologies implement as a targeted manner.

\section{B. Limitations of the Information Technology}

In the teaching process, the information technology can not overall replace the traditional teaching methods such as chalk blackboard. But in reality, many teachers have completely abandon the traditional teaching methods. Much sudden inspiration cannot be shown by the information technology, but it will be easily demonstrated by the blackboard. In addition, there are some technical deficiencies in the resulting courseware if teachers can't master the information technology, such as improper fonts and color matching, unrealistic animation effects, unreasonable interfaces, and non-standard mathematical and geometric images. So other softwares or teaching methods must be used to remedy the above deficiencies.

The teaching by the information technology should be carried out according to the characteristics of per subject. Indiscriminately applying the information technology will often be counterproductive. The corresponding teaching methods should be adopted selectively for teaching content. For the various information technology, reasonably using, exploiting its advantages to the full, and complementing each other can achieve the best teaching results.

\section{COUNTERMEASURES AND SUgGestions}

\section{A. Emancipating the Mind and Updating the Teaching Concept}

College teachers should actively accept and apply modern education techniques, and strengthen the using of the information technology and equipment from the teaching rules and the characteristics of courses. Consequently, the traditional teaching methods for teachers and the passive learning methods for students can be changed. Specifically, college teachers need master computer, network, audio and video, multimedia, application software, virtual systems and other information techniques, and then simulate the reality depending on constructivist teaching and learning theories. It will stimulate students' potential, enhance students' enthusiasm for learning, and cultivate students' innovative spirit.

\section{B. Overcoming Blindness and Enhancing Innovation}

Not all classroom teaching contents require the information technology. This requires the teachers to survey textbooks contents, understand the characteristics of courses, use it in a timely and effective manner, and not blindly apply the information technology. At the same time, we employ the information technology resources flexibly and reasonably, because the online things are not necessary and suitable. We can't be led by the information technology resources, but we can let it serve ours teaching ideas rather than trying to copy it.

\section{Reasonable Teaching Content According to Actual Needs}

In the application of the information technology, teachers still have to play a leading role in teaching, and cannot be "The tail wags the dog". The information technology as 
assisted teaching tool should be based on the actual needs of the curriculum and teaching, which should achieve that the contents is essential, well organized, concise, focused, and standardized, as well as accompanied with proper mapping, vivid color and coordinated sound. Furthermore, the contents should be instructive and interactive with feedback adjustment space. The information technology is not only used for teaching services and assist in completing the content of the syllabus. In the design and production process by the information technology, the principles of science, education, and technology should be followed. In other words, students can be attracted through advanced cognitive theory, refined contents, convenient and effective expressions, and vivid and pleasing pictures. Through the above measures, the advantages of the information technology should be exerted.

\section{Paying Attention to Teacher-student Communication and Benefits from Teaching and Learning}

A communication bridge between teachers and students need to be built. Teachers should timely and moderately communicate with students, change teaching methods and models, and improve teaching efficiency and effectiveness. Furthermore, teachers must adhere to the idea of studentoriented, appreciate interaction with students, and motivate students. The traditional teaching methods have the following advantages: inspiring questions, teacher-student interaction, personalization, instant feedback, flexible adjustment for teaching contents and methods, grasping teaching rhythm, and deepening memory and so on. To improve the teaching effectiveness of the information technology, we must reasonably integrate traditional teaching methods with the information technology, give full play to the respective advantages, improve insight and analysis of various information in the feedback, and finally optimize classroom teaching.

In short, the information technology has greatly improved the teaching efficiency and effect and developed the teaching modes. However, we must have an accurate positioning for the information technology. It is necessary to decide whether (how) to apply the information technology according to the specific curriculums. Only on a 'case by case' basis, the information technology can become our "booster" to improve the quality of teaching, rather than its "stumble".

\section{REFERENCES}

[1] Tianbo Ren, Mingxuan Lei, "Applying IT university teaching and its integrating strategies”, Northwest medical education, vol. 21, pp.20-23, Jan. 2013.

[2] Daliang Zhang, "Industriously promote universities to accelerate the deep integration of modern information technology and education”, China University Teaching, pp.7-11, Jul. 2016.

[3] Yamin $\mathrm{Hu}$, “The Integration and Improvement of College Literature Teaching and Information Technology”, China University Teaching, pp.50-53, Aug. 2017.

[4] Qian Zhang. "Innovative Exploration and Practice of Information Technology Teaching in Middle School under the Background of Maker”, Modern Educational Technology, vol. 26, pp.121-126, Feb. 2016.

[5] Shichang Xue, "Exploring the Appropriateness of Visual Content in Multimedia Teaching in Universities”, e-Education Research, pp.80-81, Mar. 2010.
[6] Guoping Mei, Xiaoqiang Liu. "Analysis on the Student-centered teaching transformation in universities: the perspective of information technology development”, Jiangsu Higher Education, pp.40-43, Jan. 2018 